\title{
Novel carbon-nanotube-enhanced composite load sensor to monitor the whole-life structural performance of buildings
}

Konrad Xuereb PhD, MSc, BE\&A (Hons), A\&CE, MIStructE, MICE, CEng, Eurlng, ARB

University College London, London, UK; Koncept ${ }^{\mathrm{X}}$ Ltd, London, UK (corresponding author: konrad.xuereb@konceptx.com)
Ivan P. Parkin PhD, FRSC, CChem, BSC (Hons), ARCS, DIC, FIMMM, CSCi

MAPS Faculty, University College London, London, UK

This paper presents research on novel load sensors for use in building structures carried out by the principal investigator in his multidisciplinary doctorate research. The sensors consist of carbon-nanotube-enhanced cement matrix and polymer composites. They record a change in electrical resistance when subjected to a change in imposed load. The sensor types are subjected to load tests, Raman spectroscopy characterisation and scanning electron microscopy tests. The gauge factors of the preferred sensor types are calculated and compared with those obtained from the literature. A critique of the preferred novel sensor system is provided.

\section{Notation}

$\% R \quad$ percentage change in the electrical resistance with respect to the unloaded state

c intercept

$\boldsymbol{F}$ force

$K \quad$ gauge factor

$m$ gradient

$\boldsymbol{R} \quad$ electrical resistance

$R_{\mathrm{s}, 0} \quad$ electrical resistance of the sample at the start of the experiment

$R_{\mathrm{s}, \mathrm{t}} \quad$ electrical resistance of the sample at any time $t$

$\Delta \varepsilon \quad$ change in strain

\section{Load sensors in buildings}

From a cost and carbon dioxide footprint perspective, the structural fabric is the most taxing part of a building to demolish and reinstate. Reutilising the structural frame while altering the rest of the building (e.g. building services) to suit new functions offers an attractive, long-term, cost-efficient solution to developers (Xuereb and Parkin, 2016).

The introduction of load sensors in buildings can allow real-time monitoring of the performance of the structural frames. Harnessing and processing of the data by way of the buildingmanagement system would provide information on the residual capacity of the building structure. This in turn would influence decisions on whether to extend, refurbish or demolish a building at any time during its lifetime.

The load sensors would be primarily introduced at the interface between the super- and the substructure and along column heights at spliced connections. They could also be introduced at beam-column connections.

Research on sensors for application in building structures has been primarily carried out on monitoring durability attributes of the structural elements. These sensors can be classified into intrinsic and extrinsic ones (Xuereb and Parkin, 2016). Intrinsic sensors refer to data-acquiring systems embedded within structural elements. Extrinsic sensors are related to data-acquiring systems that are located external to the structural components.

The relatively limited palette of construction materials normally used for building structures makes implementation of intrinsic sensing devices within the structural fabric most suitable for concrete elements. Most relevant research on intrinsic sensors in building structures has therefore focused on applications in concrete elements, with an emphasis on carbon-nanotube (CNT)-filled cement-based stress sensors (Azhari and Banthia, 2012; Dzenis, 2008; Gong et al., 2011; Han et al., 2011; Lynch et al., 2009; Njuguna et al., 2012; Yun et al., 2005; Zhang et al., 2016), nanostructured concrete (Balaguru and Chong, 2006; Bartos, 2009; Fleischer et al., 2005; Garboczi, 2009; Sanchez and Sobolev, 2010; Teizer et al., 2012), smart aggregate (Jabir and Gupka, 2011; Ou and Han, 2009; Song et al., 2007, 2008), intelligent reinforced concrete structures (Gerschenfeld et al., 2010; Inman and Grisso, 2007), self-healing materials (Hager et al., 2010; Toohey et al., 2007) and fibre-optic sensors (Habel and Krebber, 2011; Liu et al., 2011; Song and Peters, 2011). Research on extrinsic sensors for buildings has mainly focused on monitoring durability aspects of the structural elements and strain/stress monitoring. This has included strain gauges, fibre-optic sensors (Bao and Chen, 2012; Krebber et al., 2008; Lally et al., 2012) and tactile pressure sensors (Paikowsky et al., 2006).

A study carried out by Xuereb and Parkin (2016) determined that extrinsic CNT-filled cement-based sensors were the preferred data-acquiring sensors in buildings. A key challenge posed by such systems is the dispersion of the CNTs in cementitious matrices (Rehman et al., 2013; Rochez et al., 2013).

Novel CNT-enhanced cement grout load-sensing sensors were assembled consisting of CNT-enhanced cement matrix and polymer 
Smart Infrastructure and Construction

Volume 172 Issue 3
Novel carbon-nanotube-enhanced composite load sensor to monitor the whole-life structural performance of buildings

Xuereb and Parkin composites with the objective of recording a change in electrical resistance when subjected to a change in imposed load. The proposed sensors were based on dispersing multiwall CNTs (MWCNTs) in water $\left(\mathrm{H}_{2} \mathrm{O}\right)$ using ViscoFlow 1000, a superplasticiser liquid admixture based on polycarboxylate polymer technologies, prior to mixing with cement (Xuereb, 2015).

The sensors were subjected to short-term and long-term load testing, Raman spectroscopy characterisation and scanning electron microscopy (SEM) tests. The sensor type yielding the most consistent and reliable experimental results was identified. The percentage change in resistance and gauge factor were subsequently calculated and compared with those obtained from the literature.

\section{Experimental method}

The type and amount of CNTs were varied systematically to create three sensor typologies. See Table 1.

Sensor type I is built on research carried out to date on the use of polycarboxylate to disperse CNTs in cementitious mixes (Figure 1(a)). Sensor type II consists of a novel thin MWCNTenhanced polymer film with a CNT/polycarboxylate film proposed as a sandwich layer between the cement grout (Figure 1(b)). Sensor type III is developed on sensor type I by concentrating a layer of MWCNT-enhanced cement grout, effectively creating a thick-film sensor (Figure 1(c)).

Twenty-seven sensor test groups and four control test groups were prepared with three samples of each group assembled (e.g. $10 \mathrm{Ci}, 10 \mathrm{Cii}$ and $10 \mathrm{Ciii}$ for test group 10C). The samples were $20 \mathrm{~mm}$ cubes.

The type I sensors were prepared by mixing $22.5 \mathrm{ml}$ of water with $1.5 \mathrm{ml}$ polycarboxylate, and the mixture was placed on a magnetic stirrer at room temperature. MWCNTs were added to the mixture and ultrasonicated for $1 \mathrm{~h}$. The various permutations are summarised in Table 2.

The solution was manually mixed with $75 \mathrm{~g}$ of cement for $5 \mathrm{~min}$ using a spatula and placed in cube moulds. The cubes were removed after 2 days and allowed to cure for a month, and their weight was monitored. It was observed that the rate of reduction in the cube weight decreased with time, with the weight reduction occurring in the first 2 weeks after hardening and plateauing thereafter. This showed that most of the cement hydration had taken place.

\section{Table 1. Sensor typologies explored}

Type I CNT-enhanced cement grout

Type II Sandwich CNT/polycarboxylate polymer lying between two layers of non-CNT cement grout

Type III Sandwich CNT-enhanced cement grout lying between two layers of non-CNT cement grout

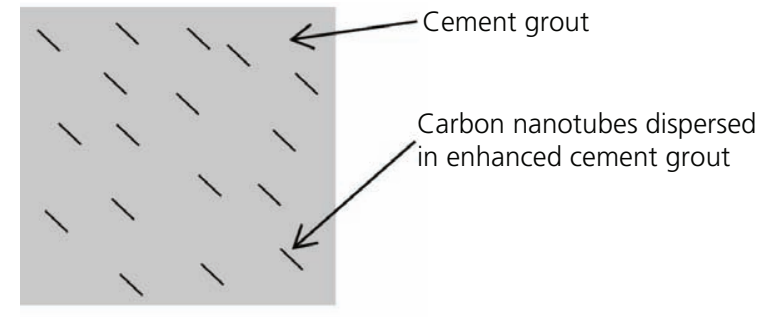

(a)

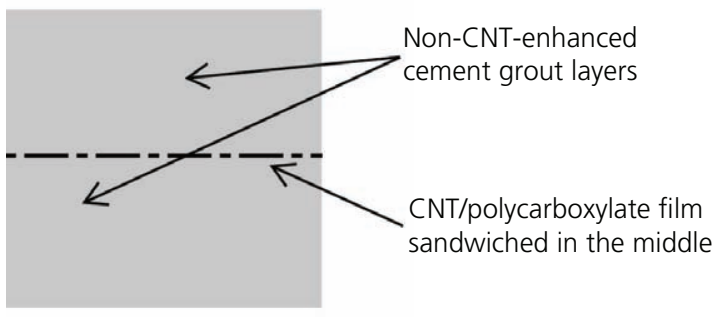

(b)

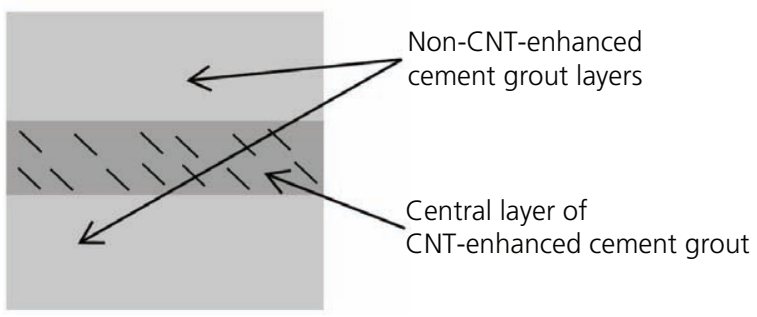

(c)

Figure 1. (a) Sensor type I; (b) sensor type II; (c) sensor type III

Once dried, the cubes were polished on two opposite faces using a fine grinder to attain a smooth finish. Silver-loaded epoxy adhesive (RS silver $10 \mathrm{~g}$ vial epoxy conductive adhesive) was then applied on two opposite surfaces and allowed to set for $48 \mathrm{~h}$ before a copper wire was soldered to it. The interface between the soldered conductive wire and the silver-pasted face was given another coat of silver paste and subsequently allowed to dry for another 2 days.

Table 2. Type I sensor samples - design mixes

\begin{tabular}{lcc|} 
Test group & Water/cement ratio & $\begin{array}{c}\text { MWCNTs (type and \% } \\
\text { by wt. of cement) }\end{array}$ \\
\hline $3 C$ & 0.3 & Sigma -0.25 \\
$4 C$ & 0.3 & Sigma -0.50 \\
$5 C$ & 0.3 & Sigma -0.75 \\
$6 C$ & 0.4 & Sigma -0.25 \\
$7 C$ & 0.4 & Sigma -0.50 \\
$8 C$ & 0.4 & Sigma -0.75 \\
$12 C$ & 0.3 & Bayer -0.25 \\
$13 C$ & 0.3 & Bayer -0.50 \\
$14 C$ & 0.3 & Bayer -0.75 \\
$15 C$ & 0.4 & Bayer -0.25 \\
$16 C$ & 0.4 & Bayer -0.50 \\
$17 C$ & 0.4 & Bayer -0.75
\end{tabular}


Smart Infrastructure and Construction

Volume 172 Issue 3
Novel carbon-nanotube-enhanced

composite load sensor to monitor the

whole-life structural performance of

buildings

Xuereb and Parkin
Table 3. Type II sensors - design mixes

\begin{tabular}{|lcc|}
\hline Test group & Water: $\mathbf{~ m l}$ & MWCNTs (type and weight) \\
\hline $9 \mathrm{C}$ & 3.75 & Sigma $-0.125 \mathrm{~g}$ \\
$10 \mathrm{C}$ & 3.75 & Sigma $-0.125 \mathrm{~g}$ \\
$11 \mathrm{C}$ & 3.75 & Bayer $-0.125 \mathrm{~g}$ \\
$30 \mathrm{C}$ & 3.75 & Sigma $-0.125 \mathrm{~g}$ \\
$31 \mathrm{C}$ & 3.75 & Bayer $-0.125 \mathrm{~g}$ \\
\hline
\end{tabular}

Type II sensors consisted of two layers of non-CNT-enhanced cement grout separated by a film of CNT/polycarboxylate polymer. See Table 3.

The samples were prepared by first forming a lower layer of nonCNT-enhanced cement grout. This was left to dry for a day before the film of CNT/polycarboxylate polymer was introduced. The film was formed by mixing $3.75 \mathrm{ml}$ water with $0.125 \mathrm{ml}$ polycarboxylate and placing the solution for $5 \mathrm{~min}$ on a magnetic stirrer at room temperature. MWCNTs $(0.125 \mathrm{~g})$ were then added to the mixture and ultrasonicated for $1 \mathrm{~h}$. This was left to dry for a day before a top layer of non-CNT-enhanced cement grout was placed.

The samples were removed from their respective moulds 2 days after the topmost layer had been placed and were allowed to cure for a month, and their weights were measured. The rate of reduction in weight was noted to reduce sharply in all the samples by the second week of curing, flattening thereafter. This demonstrated that most of the moisture had reacted with the cement. Silver epoxy paste was then applied on two opposite surfaces and allowed to set for $48 \mathrm{~h}$.

Type III sensors consisted of two layers of non-CNT-enhanced cement grout separated by a layer of CNT-enhanced cement grout. The various combinations of type III sensors are summarised in Table 4.

The samples were formed by first placing a lower layer of nonCNT-enhanced cementitious grout. This was left to dry for a day before a central layer of CNT-enhanced cementitious grout, similar to sensor type I, was placed above the base layer and allowed to dry for a day. A top layer of non-CNT-enhanced

Table 4. Type III sensor samples - design mixes

\begin{tabular}{|lcc|}
\hline Test group & Water/cement ratio & $\begin{array}{c}\text { MWCNTs (type and \% } \\
\text { by wt. of cement) }\end{array}$ \\
\hline $18 C$ & 0.4 & Sigma -2.0 \\
$19 C$ & 0.4 & Bayer -2.0 \\
$22 C$ & 0.4 & Sigma -1.0 \\
$23 C$ & 0.4 & Bayer -1.0 \\
$24 C$ & 0.4 & Sigma -0.5 \\
$25 C$ & 0.4 & Bayer -0.5 \\
$26 C$ & 0.3 & Bayer -2.0 \\
$27 C$ & 0.3 & Bayer -0.5 \\
$28 C$ & 0.3 & Sigma -2.0 \\
$29 C$ & 0.3 & Sigma -0.5 \\
\hline
\end{tabular}

cement grout was then placed above. The samples were removed from the moulds 2 days after the topmost layer had been placed. The cubes were then cured for a month, and their weights were measured. The rate of reduction in weight was noticed to reduce significantly by the second week of curing. This indicated that the majority of the cement hydration had taken place. Silver epoxy paste was applied on opposite polished surfaces.

Sample groups 1C, 2C, 20C and 21C, devoid of any CNTs in the mix, served as control samples. Cube groups $1 \mathrm{C}$ and $2 \mathrm{C}$ had a water/cement ratio of 0.3 , while samples $20 \mathrm{C}$ and $21 \mathrm{C}$ had a water/cement ratio of 0.4 . The objectives of preparing the control samples were

- to allow an appreciation of the minimum compressive stress that the samples could be subjected to prior to failure

n to assess whether the samples recorded any electrical resistance during the compressive tests.

The control samples were dried for a month, and their weights were measured. The rate of reduction in weight was observed to plateau after 2 weeks. Silver epoxy paste was then applied on the opposite polished surfaces.

\subsection{Testing procedure}

The compressive tests were held within the laboratory of the Department of Civil, Environmental and Geomatic Engineering at University College London. A Controls Advantest 9 compression test machine was used. Low-voltage displacement transducers on either side of the sample being tested were used to measure the displacement under loading. The transducers were positioned equidistant from the sample. Each sample was centred under the load cell. Measurements of the electrical resistance of the loaded test samples were carried out using a multimeter. A voltage was applied by way of the multimeter, and a resistance measured if the material was conductive.

The electrical resistance of the control samples, devoid of CNTs, was initially measured without any loading. The control samples were then subjected to the same load as the test sensor cubes to eliminate the possibility that characteristics unrelated to the CNTs were affecting any sensing characteristics obtained in the experiments.

Type I sensor samples were tested in two orthogonal directions. Type II and III sensor samples were loaded with the electrodes perpendicular to the load cell only.

In the 102 short-term compressive load tests carried out, the samples were subjected to cyclic loading, followed by stepped loading, with the electrical resistance recorded at frequent intervals. The primary objective of the short-term loading cycle tests was to identify test families that provided a change in electrical resistance when the loading changed. The shortlisted samples were then tested under long-term compressive loading, 
with the loading increased and kept for an hour and then unloaded, with the cycle repeated twice. The electrical resistance was noted regularly during the experiments.

Raman spectroscopy characterisation was carried out using a Renishaw inVia Raman spectrometer (with a laser wavelength of $514.5 \mathrm{~nm}$ ) on the following samples:

type I sensors $3 \mathrm{Cii}$, 4Cii, 5Ciii, $8 \mathrm{Ci}$, 14Ciii and $17 \mathrm{Ci}$

- type II sensors $10 \mathrm{Cii}, 30 \mathrm{Ci}$ and $31 \mathrm{Cii}$

- type III sensors 19Cii, 23Ciii, 27Ci and 28Cii.

SEM characterisation, using a Jeol JSM-6700F field-emission scanning electron microscope, was carried out to investigate the dispersion of the nanotubes in the following samples:

- type I sensor $17 \mathrm{Cii}$

- type II sensors 30Cii and $31 \mathrm{Ci}$

- type III sensor 19Cii.

\section{Results and discussion}

\subsection{Control samples (devoid of CNTs)}

The electrical resistance measured in all control samples when the leads were connected to the multimeter prior to testing was higher than $20 \mathrm{M} \Omega$, indicating that the control samples were nonconducting. The resistances at the interface between the silver paste and the test material and at the interface between the conducting wire and the silver paste were on the order of a few ohms. Given the anticipated resistances on the order of kiloohms for the sensor sample tests, these resistances were neglected, and a 2-point resistance measurement deemed satisfactory for the experiments.

Control samples $1 \mathrm{Ci}, 2 \mathrm{Ci}, 20 \mathrm{Ciii}$ and 21Ciii were loaded to failure at a compressive load of $>16 \mathrm{kN}$. A limit of $4.5 \mathrm{kN}$ was deduced for the $20 \mathrm{~mm}$ cube samples. Control samples $20 \mathrm{C}$ and $21 \mathrm{C}$ were then loaded under short-term uniaxial compressive loading cycle, with the electrodes both perpendicular and parallel to the load cells. The control samples provided a resistance of $>20 \mathrm{M} \Omega$ and were thus deemed not to be conductive.

\subsection{Load test results}

3.2.1 Type I sensors: CNT-enhanced cement grout samples Fifty-seven short-term load tests were performed on the type I sensors. Most test samples were loaded in two orthogonal directions. Seventeen tests produced a change in electrical resistances with a change in loading. The remaining 40 samples either fractured or did not demonstrate any change in resistance.

The following type I sensor samples were shortlisted for longterm load tests:

n electrodes perpendicular to load cells: $8 \mathrm{Cii}, 16 \mathrm{Ci}$ and $17 \mathrm{Ci}$

- electrodes parallel to load cells: $8 \mathrm{Ciii}, 13 \mathrm{Ci}, 16 \mathrm{Ci}, 17 \mathrm{Ci}$ and 17Cii.
A strong baseline drift in resistance was noticed in most of the type I sensors before they were loaded. The samples were therefore tested, acknowledging that this drift in measurement was present. Most of the type I sensors gave high resistances $(>20 \mathrm{M} \Omega)$, with less coherent results under long-term load tests.

It is hypothesised that the nanotubes in type I sensors move closer under loading, resulting in a change in electrical resistance through a better percolation pathway for electrons. However, the small amounts of CNTs dispersed in the matrix result in distances between the nanotubes in the cement grout matrix that are significantly larger than the change in distance between said nanotubes.

The high resistance produced by these samples accompanied by the small and inconsistent change in resistance under a change in loading correlates with this model. The drift experienced in the measured resistance could be described by the inconsistent conducting pathways between the nanotubes in this model, which would also explain why this drift was also present as the samples were loaded.

\subsubsection{Type II sensors: sandwich samples consisting of non-CNT-enhanced cement grout outer layers with a film of CNT/polycarboxylate polymer in between}

Nine short-term load tests were carried out on type II sensors. The type II sensors experienced a change in resistance with a change in loading. The electrical resistances measured in all these samples were on the kiloohm scale. Furthermore, no significant baseline drift in resistance was noticed in any of these test groups.

The samples gave a very consistent change in resistance with change in loading, with the resistance decreasing when the load increased and vice versa.

Some type II sensors were damaged (due to handling) after the short-term load tests and test groups C30 and C31 were therefore assembled identically to groups $\mathrm{C} 10$ and $\mathrm{C} 11$, respectively. These were tested under long-term loading and experienced a consistent change in resistance with a change in loading. The electrical resistance measured was on the kiloohm scale, varying between 0.4 and $0.8 \mathrm{k} \Omega$ (see Figure 2). No significant baseline drift in the resistance measured was noticed.

With reference to Figure 3, the nanotubes in the central film of $\mathrm{CNT}$ /polycarboxylate polymer move closer together as the sample experiences compressive strain from the axial load, increasing the conduction by tunnelling between the nanotubes in the middle CNT polymer film. The strain-sensing characteristics are thus attributed to both intertube resistances and the intrinsic resistance of the CNTs. As a result, a significantly more pronounced change in resistance is produced in these sensors when compared with that in the type I sensors. These tests showed that most of the type II sensors gave a good correlation between a change in resistance and a change in load during the test loads. 


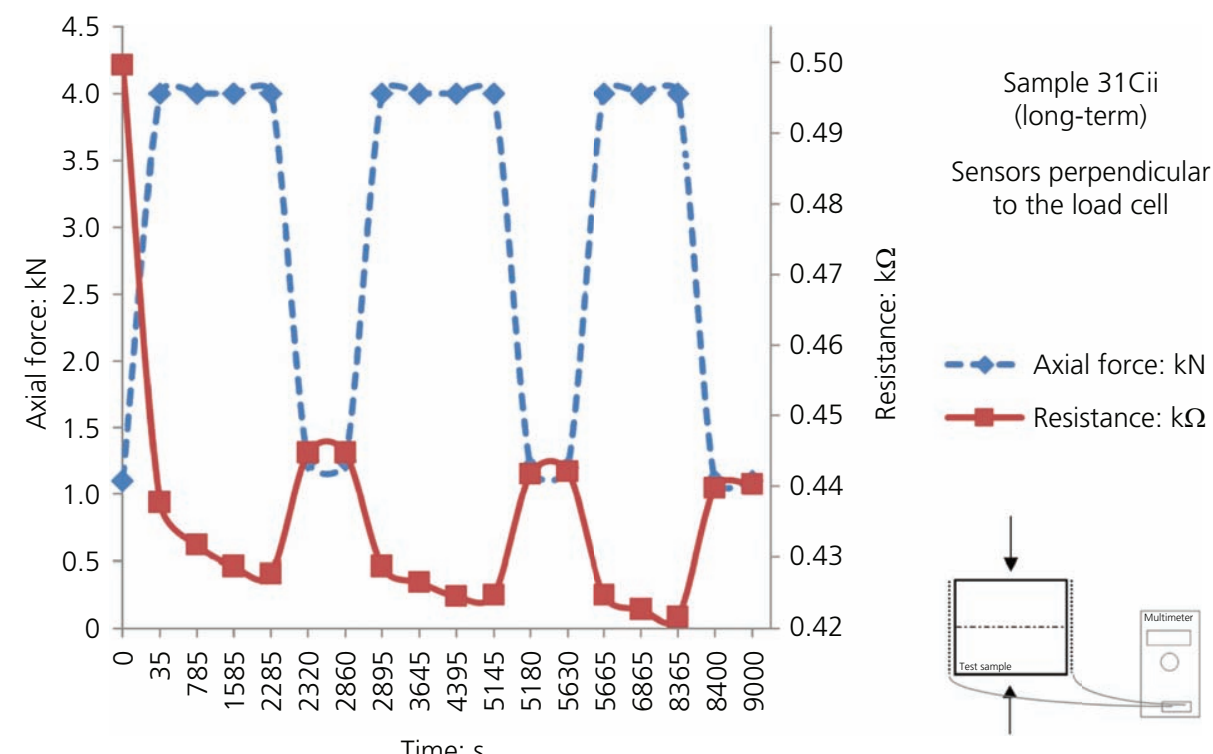

Figure 2. Type II sensor sample 31Cii long-term loading - test results. The central CNT/polycarboxylate film in sample 31Cii was formed by mixing $3.75 \mathrm{ml}$ water with $0.125 \mathrm{~g}$ CNT(Bayer)

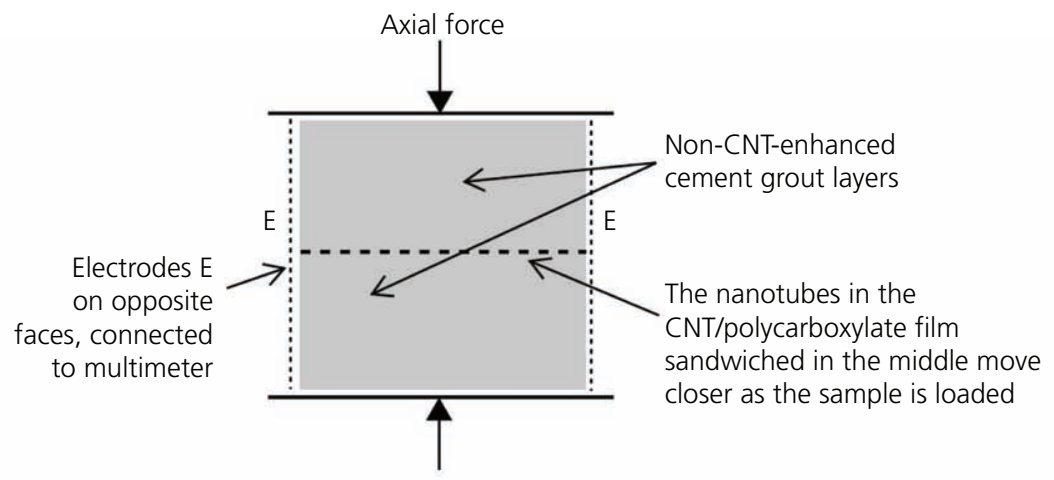

(a)

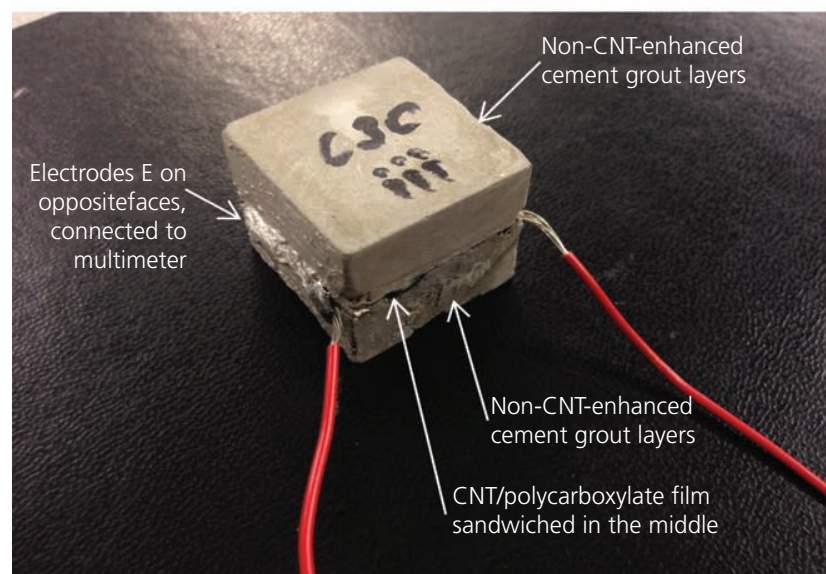

(b)

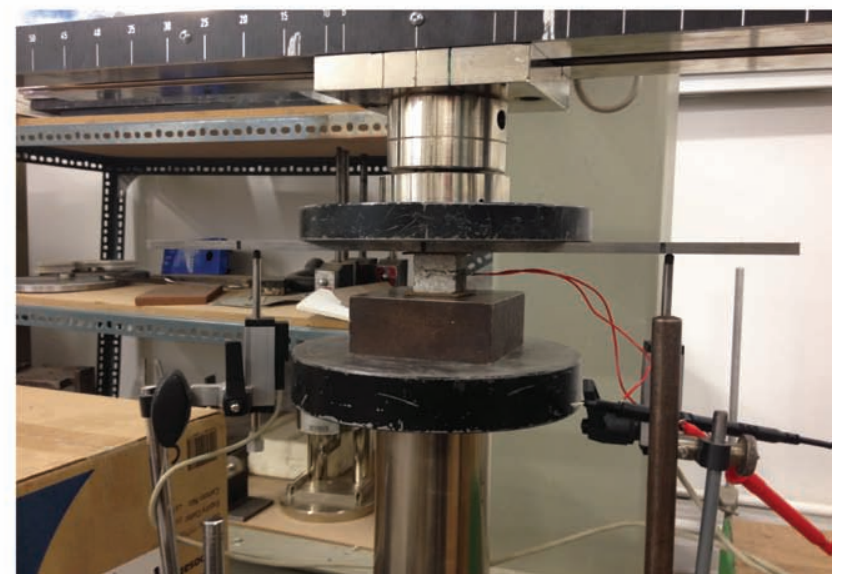

(c)

Figure 3. (a) Theoretical model of interpretation of the behaviour of type II sensor samples under compressive loading; (b) assembled type II sensor sample 30Ciii; (c) type II sensor sample C30i during long-term tests 
Smart Infrastructure and Construction

Volume 172 Issue 3
Novel carbon-nanotube-enhanced

composite load sensor to monitor the

whole-life structural performance of

buildings

Xuereb and Parkin
The magnitudes of electrical resistance of test groups $30 \mathrm{C}$ and $31 \mathrm{C}$ were similar to those experienced by test groups $10 \mathrm{C}$ and $11 \mathrm{C}$ in the short-term tests, demonstrating the repeatability of the tests.

In all the tests carried out on the type II sensor samples, the change in resistance measured was sensitive to the change in load. With reference to Table 5 and Figure 4, the resistances measured in test groups $30 \mathrm{C}$ and $31 \mathrm{C}$ were found to be proportional to the applied force in accordance with the following equation:

1. $\boldsymbol{R}=m \boldsymbol{F}+c$

where $\boldsymbol{R}$ is in kiloohms and $\boldsymbol{F}$ is in kilonewtons.

An important conclusion is that the slopes of resistance-againstload plots are remarkably consistent even though the intercepts are different. Knowing the slope and acknowledging that each sensor differs only in the intercept constant, the latter can be deduced from the known supporting load once the sensors are installed in a project and construction completed, allowing the load sensor to be calibrated fully.

\subsubsection{Type III sensors: sandwich samples consisting of} non-CNT-enhanced cement grout outer layers with a layer of CNT-enhanced cement grout in between

Half of the 30 short-term load tests carried out on type III sensors experienced no change in resistance. Furthermore, eight samples broke during the tests. The electrical resistances measured in most type III sensors were on the megaohm scale. A strong baseline

Table 5. Derived values of gradient $m$ and intercept $c$ of Equation 1 from long-term tests on type II sensor groups 30C and 31C

\begin{tabular}{lcc} 
& $\boldsymbol{m}$ & $\boldsymbol{c}$ \\
\hline $30 \mathrm{Ci}$ & -0.010 & 0.62 \\
$30 \mathrm{Cii}$ & -0.016 & 2.43 \\
$31 \mathrm{Ci}$ & -0.011 & 0.77 \\
$31 \mathrm{Cii}$ & -0.010 & 0.48 \\
31Ciii & -0.008 & 0.56
\end{tabular}

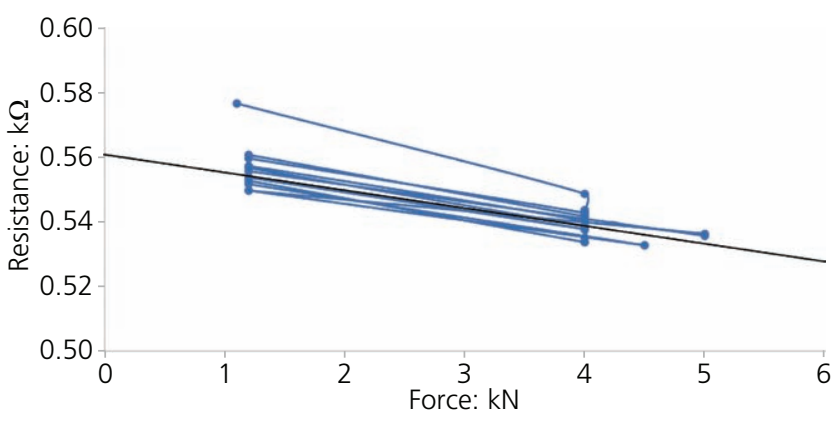

Figure 4. Type II sensor sample 31Ciii. Electrical resistance measured plotted against applied force drift in resistance was noticed in most samples before and during loading.

The poor performance of the type III sensors is hypothesised to be similar to that of the type I sensors as described in Section 3.2.1.

\subsection{Raman spectroscopy characterisation}

The Raman spectra derived for the type I and III sensors did not demonstrate a predominant band. This is a marker either of poor dispersion of the nanotubes or that the conductive qualities of the nanotubes are being attenuated when dispersed in the cementitious matrix.

Type II sensors 10Ciii, 30Ci and 31Cii assessed under a Raman spectrometer demonstrated frequencies similar to those of MWCNTs, with the two main typical graphite bands observed at $1580 \mathrm{~cm}^{-1}$ ( $\mathrm{G}$ band), assigned to the in-plane vibration of the $\mathrm{C}-\mathrm{C}$ bond ( $\mathrm{G}$ band) and with a shoulder around $1604 \mathrm{~cm}^{-1}$, typical of defective graphite-like materials, and at $1342 \mathrm{~cm}^{-1}$ (D band), activated by the presence of disorder in carbon systems. The Raman spectra of samples 30Ci (Figure 5) and 31Cii also exhibited a band at $2683 \mathrm{~cm}^{-1}$, called the $G^{\prime}$ band and attributed to the overtone of the $\mathrm{D}$ band.

All type II sensor samples assessed under a Raman spectrometer produced the same frequency as that of the respective MWCNTs. This indicated that the CNT characteristics were not damaged in the process of forming the sample and were unaltered.

\subsection{SEM characterisation}

Nanotubes were not clearly identifiable in the SEM tests carried out on type I sensor 17Cii and type III sensor 19Cii. The absence of CNTs observed in the tests on these two samples could be due to poor dispersion of the nanotubes in the cement grout matrix, resulting in the lack of conductive paths in the cement matrix.

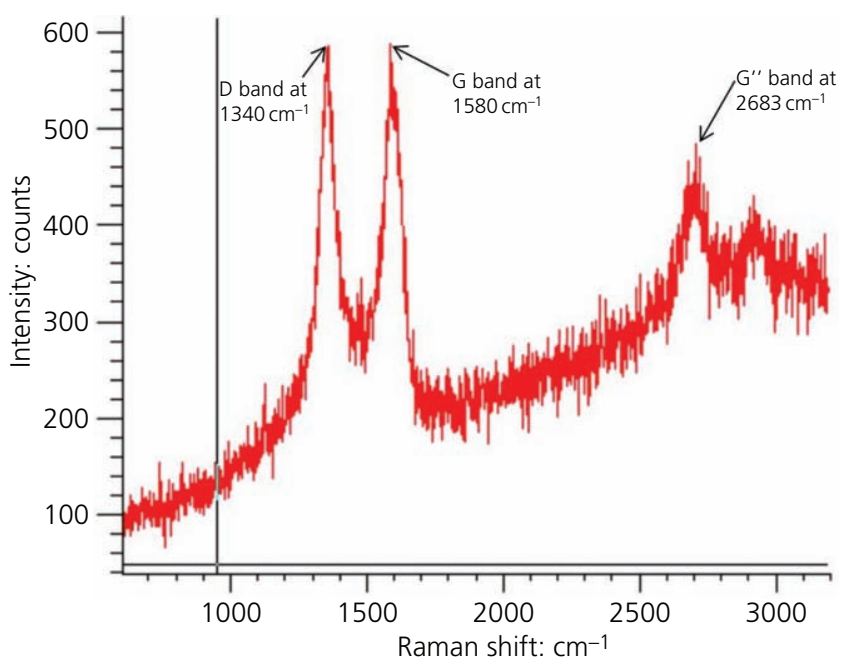

Figure 5. Raman spectrum of type II sensor sample $30 \mathrm{Ci}$ 
Smart Infrastructure and Construction

Volume 172 Issue 3
Novel carbon-nanotube-enhanced

composite load sensor to monitor the

whole-life structural performance of

buildings

Xuereb and Parkin

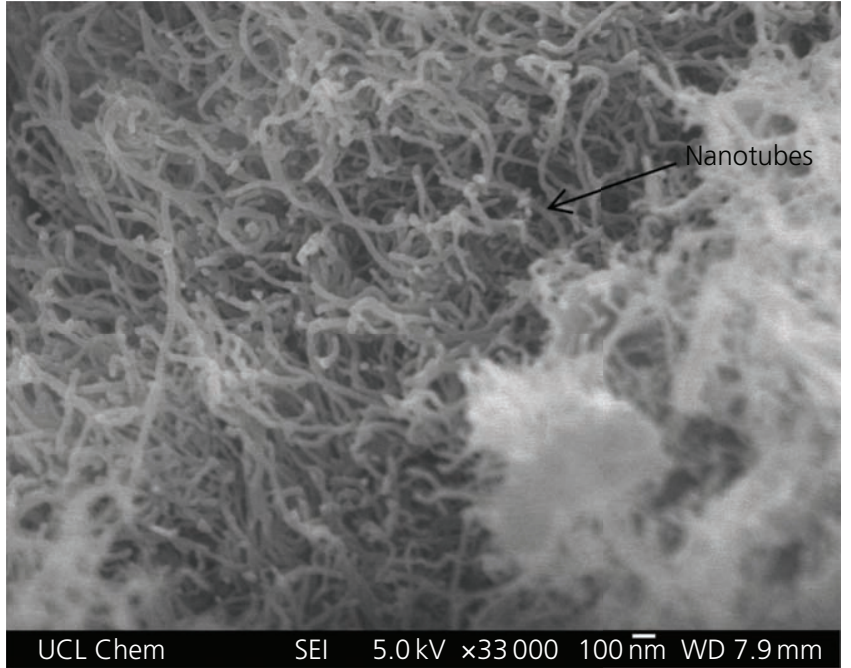

Figure 6. Type II sensor sample 30Cii - SEM results

These samples provided high resistance when subjected to longterm loads.

Nanotubes could be identified when type II samples 30Cii and $31 \mathrm{Ci}$ were assessed under a scanning electron microscope (see Figure 6). These tests demonstrated that even though the nanotubes in the $\mathrm{CNT} /$ polycarboxylate film tended to conglomerate in bundles, the nanotubes were well dispersed throughout the sample and individual nanotubes forming the clumps could be observed.

\subsection{Critique of the results}

The results from the long-term load tests carried out on the shortlisted type I, II and III sensors were similar to the findings from the respective short-term tests. All type I and III sensors demonstrated low sensitivity to change in resistance under cyclic test loading. Type I and III sensors also produced considerable drift in electrical resistance measurements, before and during the experiments. SEM tests on type I and III sensor samples showed poor dispersion of the nanotubes.

Sensor type II samples produced the most consistent results vis-àvis change in resistance measured against load fluctuations. Sensor type II samples also gave the most pronounced change in resistance measured and lacked any significant drift in the measurements. Furthermore, the short- and long-term test results of type II samples were similar in magnitude. The SEM tests carried out on the type II sensors demonstrated good dispersion of the nanotubes throughout the CNT/polymer film. Raman spectroscopy carried out on the type II sensors produced the same frequency as that of the respective nanotubes, indicating that there was no reaction on a surface basis.

Overall, type II sensors $30 \mathrm{C}$ and $31 \mathrm{C}$ produced the best results.

\subsubsection{Percentage change in resistance}

The percentage change in the electrical resistance $(\% R)$ with respect to the unloaded state was determined using the following equation:

2. $\% R=\left[\left(R_{\mathrm{s}, \mathrm{t}}-R_{\mathrm{s}, 0}\right) / R_{\mathrm{s}, 0}\right] \times 100$

where $R_{\mathrm{S}, \mathrm{t}}$ is the electrical resistance of the sample at any time $t$ and $R_{\mathrm{s}, 0}$ is the electrical resistance of the sample at the start of the experiment. This is taken as the preload of the samples.

The percentage change in resistance experienced by $30 \mathrm{C}$ and $31 \mathrm{C}$ test samples varied between approximately 3 and $10 \%$ as the samples were subjected to cyclic loads between 1.5 and $6.0 \mathrm{kN}$, averaging approximately $1 \%$ change in resistance in the five samples assessed to every $1 \mathrm{MPa}$ increase/decrease in applied uniaxial stress.

\subsubsection{Gauge factor}

The gauge factors of the type II sensors $30 \mathrm{Ci}, 30 \mathrm{Cii}, 31 \mathrm{Ci}, 31 \mathrm{Cii}$ and 31Ciii were determined to provide a comparative assessment of the sensitivity of the novel sensors created.

The gauge factor $(K)$ is the fractional change in electrical resistance per unit strain and can be determined by using the following equation:

3. $K=\left\{\left[\left(R_{\mathrm{s}, \mathrm{t}}-R_{\mathrm{s}, 0}\right) / R_{\mathrm{s}, 0}\right] /(\Delta \varepsilon)\right\}$

where $\Delta \varepsilon$ is the change in strain equating to the change in displacement divided by the length of the sample. $R_{\mathrm{s}, \mathrm{t}}$ and $R_{\mathrm{s}, 0}$ are defined as in Equation 2.

The higher the gauge factor $(K)$, the more sensitive the strain gauge is. The gauge factors obtained from the type II sensors were up to 12 . As a comparison, metal foil strain gauges typically have a gauge factor of 2 (Loh et al., 2006).

The gauge factors attained from the CNT/polycarboxylate polymer film indicated that the MWCNTs in sensor type II responded piezoresistively to small changes in strain, given the high modulus of elasticity of the cement grout.

\subsubsection{Comparison of gauge factors of type II sensors with those from the literature}

The gauge factors obtained from the type II sensors were compared with those obtained from the literature on CNT/polymer films. Gauge factors have been shown to vary widely with the electrical structure of CNTs (Bauhofer and Kovacs, 2009; Cullinan and Culpepper, 2010; Grossiord et al., 2008; Hu et al., 2010, 2013; Kang et al., 2006; Kanoun et al., 2014; Loh et al., 2007, 2008; Oliva-Avilés et al., 2011; Park et al., 2008; Pham et al., 2008; Wang and Cheng, 2014; Wichmann et al., 2008, 2009; Yang and Lu, 2013; Yin et al., 2011). 
The best gauge factor in the review paper by Yin et al. (2011) was found to be 22.4. Gauge factors for CNT films of up to 80 were also reported (Cullinan and Culpepper, 2010). In other research works, gauge factors of 125 and 65 were found for iodine-doped and iodine-undoped CNTs films less than 500 microstrains, respectively (Wang and Cheng, 2014). Hu et al. (2010, 2013) obtained a gauge factor of 65 for pristine CNT thin films under normal temperature. Bu et al. (2010) demonstrated that the sonication time strongly influenced the quality of CNT dispersion. In a research by Dinh-Trong et al. (2009), MWCNTbased films fabricated by solution drop-casting on defined rectangular shapes, strain sensitivities of $4,7.5$ and 12.5 were reported for films based on MWCNTs dispersed in sodium dodecyl sulfate (a surfactant), deoxycholic acid and polyethelene oxide, respectively.

Pham et al. (2008) reported changes in the resistivity of polymer/ MWCNT films subjected to tensile strains. Gauge factors were found to increase with decreasing MWCNT concentrations, reaching over 15 at $1 \mathrm{wt}$ \% MWCNT. Wang and Cheng (2014) carried out compression load tests on CNT silicone-matrix composites, transversely sealed. The absolute values of the gauge factor were observed to increase with the decrease in the CNT content. A gauge factor of 4.86 was reported for $3 \mathrm{wt}$ \% CNTs, while a gauge factor of 2.35 was reported for $8 \mathrm{wt}$ \% CNTs. A gauge factor of 7 was reported when MWCNT/polycarbonate nanocomposite fillers were subjected to tensile strain (Ramaratnam and Jalil, 2006).

\section{Concluding discussion}

Three sensors, types I, II and III, were researched based on an extrinsic CNT-enhanced cement grout with a polycarboxylate polymer used as a dispersant.

Novel sensor type II produced the strongest correlation between the change in electrical resistance and the change in loading, without experiencing any significant drift.

A key differentiator of the type II CNT/polycarboxylate polymer film sensor was the consistent correlation between the change in load and the change in resistance measured.

Another important characteristic of the type II sensor was the consistent magnitude of resistances measured from samples of the same test group. Repeatability of the experiments was also a differentiator pertaining to type II sensors.

The absence of any significant drift in resistance measured before and during the load tests enhanced the reliability of the type II sensors. All the tests on type I and III samples produced pronounced drifts before and during the tests.

The relatively high gauge factors obtained by type II sensors were another important factor in the potential ubiquitous use of the sensors in building structures.
The type II CNT/polycarboxylate polymer film was therefore determined to be the preferred sensor type. This would be placed extrinsically in key locations in the structural frame of buildings in real-life scenarios and linked to the building-management system.

\section{REFERENCES}

Azhari F and Banthia N (2012) Cement-based sensors with carbon fibres and carbon nanotubes for piezoresistive sensing. Cement and Concrete Composites 34(7): 866-873, https://doi.org/10.1016/j.cemconcomp. 2012.04.007.

Balaguru P and Chong K (2006) Nanotechnology and concrete: research opportunities. In Nanotechnology of Concrete: Recent Developments and Future Perspectives (Sobolev K and Shah SP (eds)). American Concrete Institute, Farmington Hills, MI, USA, pp. 15-28.

Bao X and Chen L (2012) Recent progress in distributed fibre optic sensors - review paper. Sensors 12(7): 8601-8639, https://doi.org/10. 3390/s120708601.

Bartos PJM (2009) Nanotechnology in construction: a roadmap for development. In Nanotechnology in Construction 3 (Bittnar Z, Bartos PJM, Němeček J, Šmilauer V and Zeman J (eds)). Springer, Berlin, Germany, pp. 15-26.

Bauhofer W and Kovacs JZ (2009) A review and analysis of electrical percolation in carbon nanotube polymer composites. Composites Science and Technology 69(10): 1486-1498, https://doi.org/10.1016/j. compscitech.2008.06.018.

Bu L, Steiz J and Kanoun O (2010) Influence of processing parameters on properties of strain sensors based on carbon nanotube films. In Proceedings of the 7th International Multi-conference on Systems, Signals and Devices - Sensors, Circuits \& Instrumentation Systems. IEEE, New York, NY, USA, pp. 27-30.

Cullinan MA and Culpepper ML (2010) Carbon nanotubes as piezoresistive microelectromechanical sensors: theory and experiment. Physical Review B 82(11): article 115428, https://doi.org/10.1103/ PhysRevB.82.115428.

Dinh-Trong T, Steitz J, Bu L and Kanoun O (2009) Influence of the composition of MWCNTs layers on the properties of strain gauges. In Proceedings of the 9th IEEE Conference on Nanotechnology. IEEE, New York, NY, USA, pp. 477-480.

Dzenis Y (2008) Structural nanocomposites. Science 319(5862): 419-420, https://doi.org/10.1126/science.1151434.

Fleischer T, Decker M and Fiedeler U (2005) Assessing emerging technologies - methodological challenges and the case of nanotechnologies. Technological Forecasting and Social Change 72(9): 1112-1121, https://doi.org/10.1016/j.techfore.2004.10.005.

Garboczi EJ (2009) Concrete nanoscience and nanotechnology: definitions and applications. In Nanotechnology in Construction 3 (Bittnar Z, Bartos PJM, Němeček J, Šmilauer V and Zeman J (eds)). Springer, Berlin, Germany, pp. 81-88.

Gerschenfeld N, Samouhos S and Nordman B (2010) Intelligent infrastructure for energy efficiency. Science 327: 1086-1088.

Gong $\mathrm{H}$ et al. (2011) Preparation and properties of cement based piezoelectric composites modified by CNT's. Current Applied Physics 11(3): 653-656, https://doi.org/10.1016/j.cap.2010.10.021.

Grossiord N et al. (2008) High-conductivity polymer nanocomposites obtained by tailoring the characteristics of carbon nanotube fillers. Advanced Functional Materials 18(20): 3226-3234, https://doi.org/10. 1002/adfm.200800528.

Habel W and Krebber K (2011) Fiber-optic sensor applications in civil and geotechnical engineering. Photonic Sensors 1(3): 268-280, https:// doi.org/10.1007/s13320-011-0011-x.

Hager M, Greil P, Leyens C, Zwaag S and Schubert U (2010) Self-healing materials. Advanced Materials 22(47): 5424-5430, https://doi.org/10. 1002/adma.201003036. 
Han B, Yu X, Zhang K, Kwon E and Ou J (2011) Sensing properties of CNTfilled cement-based stress sensors. Journal of Civil Structural Health Monitoring 1: 17-24, https://doi.org/10.1007/s13349-010-0001-5.

Hu N, Karube Y, Arai M et al. (2010) Investigation on sensitivity of a polymer/carbon nanotubes composite strain sensor. Carbon $\mathbf{4 8 ( 3 )}$ 680-687, https://doi.org/10.1016/j.carbon.2009.10.012.

Hu N, Itoi T, Akagi T et al. (2013) Ultrasensitive strain sensors made from metal-coated carbon nanofiller/epoxy composites. Carbon 51: 202-212, https://doi.org/10.1016/j.carbon.2012.08.029.

Inman D and Grisso B (2007) Adaptive structures for structural health monitoring. In Adaptive Structures: Engineering Applications (Wagg D, Bond I, Weaver P and Friswell M (eds)). Wiley, Chichester, UK, pp. 1-32.

Jabir S and Gupka N (2011) Thick-film ceramic strain sensors for structural health monitoring. IEEE Transactions on Instrumentation and Measurement 60(11): 3669-3676.

Kang I, Schulz MJ, Kim JH, Shanov V and Shi D (2006) A carbon nanotube strain sensor for structural health monitoring. Smart Materials and Structures 15: 737-748, https://doi.org/10.1088/0964-1726/15/3/009.

Kanoun O, Müller C, Benchirouf A et al. (2014) Flexible carbon nanotube films for high performance strain sensors. Sensors 14(6): 10042-10071, https://doi.org/10.3390/s140610042.

Krebber K, Lenke P, Liehr S, Witt J and Shukar M (2008) Smart technical textiles with integrated POF sensors. Proceedings of SPIE 6933 V1-V15, https://doi.org/10.1117/12.776758.

Lally EM, Reaves, Horrell E, Klute S and Froggatt ME (2012) Fiber optic shape sensing for monitoring of flexible structures. Proceedings of SPIE 8345: article 83452Y, https://doi.org/10.1117/12.917490.

Liu W, Wang H, Zhou Z et al. (2011) Optical fiber based sensing system design for the health monitoring of multi-layered pavement structure. Proceedings of SPIE 8199: K1-K8, https://doi.org/10.1117/12.904779.

Loh KJ, Lynch JP and Kotov NA (2006) Mechanical-electrical characterization of carbon-nanotube thin films for structural monitoring applications. Proceedings of SPIE 6174(1): article 61741Z, https://doi.org/10.1117/12.658896.

Loh KJ, Kim J, Lynch JP, Kam NWS and Kotov NA (2007) Multifunctional layer-by-layer carbon nanotube-polyelectrolyte thin films for strain and corrosion sensing. Smart Materials and Structures 16(2): 429-438, https://doi.org/10.1088/0964-1726/16/2/022.

Loh KJ, Lynch JP, Shim BS and Kotov NA (2008) Tailoring piezoresistive sensitivity of multilayer carbon nanotube composite strain sensors. Journal of Intelligent Materials Systems and Structures 19(7): 747-764, https://doi.org/10.1177/1045389X07079872.

Lynch JP, Loh KJ, Hou TC and Kotov N (2009) Nanocomposite sensing skins for distributed structural sensing. In Nanotechnology in Construction 3 (Bittnar Z, Bartos PJM, Němeček J, Šmilauer V and Zeman J (eds)). Springer, Berlin, Germany, pp. 303-308.

Njuguna MK, Yan C, Hu N, Bell JM and Yarlagadda PK (2012) Sandwiched carbon nanotube film as strain sensor. Composites: Part B 43(6): 2711-2717, https://doi.org/10.1016/j.compositesb.2012.04.022.

Oliva-Avilés Al, Avilés F and Sosa V (2011) Electrical and piezoresistive properties of multi-walled carbon nanotube/polymer composite films aligned by an electric field. Carbon 49(9): 2989-2997, https://doi.org/ 10.1016/j.carbon.2011.03.017.

Ou J and Han B (2009) Piezoresistive cement-based strain sensors and self-sensing concrete components. Journal of Intelligent Material Systems and Structures 20(3): 329-336, https://doi.org/10.1177/ 1045389X08094190.

Paikowsky S, Palmer CJ and Rolwes LE (2006) The use of tactile sensor technology for measuring soil stress distribution. In GeoCongress 2006: Geotechnical Engineering in the Information Technology Age (DeGroot DJ, DeJong JT, Frost D and Baise LG (eds)). American Society of Civil Engineers, Reston, VA, USA.

Park M, Kim H and Youngblood JP (2008) Strain-dependent electrical resistance of multi-walled carbon nanotubes/polymer composite films.
Nanotechnology 19(5): article 055705, https://doi.org/10.1088/09574484/19/05/055705

Pham GT, Park Y, Liang Z, Zhang C and Wang B (2008) Processing and modelling of conductive thermoplastic/carbon nanotubes films for strain sensing. Composites Part B: Engineering 39(1): 209-216, https://doi.org/10.1016/j.compositesb.2007.02.024.

Ramaratnam A and Jalil N (2006) Reinforcement of piezoelectric polymers with carbon nanotubes: pathway to next-generation sensors. Journal of Intelligent Material Systems and Structures 17(3): 199-208, https://doi.org/10.1177/1045389X06055282.

Rehman A et al. (2013) A facile and novel approach towards carboxylic acid functionalization of multiwalled carbon nanotubes and efficient water dispersion. Materials Letters 108: 253-256, https://doi.org/10. 1016/j.matlet.2013.07.009

Rochez O, Zorzini G, Amadou J, Claes M and Richel A (2013) Dispersion of multiwalled carbon nanotubes in water by lignin. Journal of Materials Science 48: 4962-4964, https://doi.org/10.1007/s10853-013-7278-9.

Sanchez F and Sobolev K (2010) Nanotechnology in concrete - a review. Construction and Building Materials 24(11): 2060-2071, https://doi. org/10.1016/j.conbuildmat.2010.03.014.

Song YJ and Peters KJ (2011) A self-repairing polymer waveguide sensor. Smart Materials and Structures 20(6): article 065005, https://doi.org/ 10.1088/0964-1726/20/6/065005

Song G, Gu H and Mo YL (2007) Smart aggregates: a distributed intelligent multi-purpose sensor network (DIMSN) for civil structures. In Proceedings of the 2007 IEEE International Conference on Networking, Sensing and Control. IEEE, New York, NY, USA, pp. 775-780.

Song G, Gu H and Mo YL (2008) Smart aggregates: multi-functional sensors for concrete structures - a tutorial and a review. Smart Materials and Structures 17(3): article 033001, https://doi.org/10. 1088/0964-1726/17/3/033001.

Teizer J, Venugupol M, Teizer W and Felkl K (2012) Nanotechnology and its impact on construction: bridging the gap between researchers and industry professionals. Journal of Construction Engineering and Management 138(5): 594-604, https://doi.org/10.1061/(ASCE)CO. 1943-7862.0000467.

Toohey K, Sottos N, Lewis J, Moore J and White S (2007) Self-healing materials with microvascular networks. Nature Materials 6: 581-585, https://doi.org/10.1038/nmat1934.

Wang $L$ and Cheng $L$ (2014) Piezoresistive effect of a carbon nanotube silicone-matrix composite. Carbon 71: 319-331, https://doi.org/10. 1016/j.carbon.2014.01.058.

Wichmann MHG, Buschhorn ST, Böger L, Adelung R and Schulte K (2008) Direction sensitive bending sensors based on multi-wall carbon nanotube/epoxy nanocomposites. Nanotechnology 19(47): article 475503, https://doi.org/10.1088/0957-4484/19/47/475503.

Wichmann MHG, Buschhorn ST, Gehrmann J and Schulte K (2009) Piezoresistive response of epoxy composites with carbon nanoparticles under tensile load. Physics Review B 80(24): article 245437, https:// doi.org/10.1103/PhysRevB.80.245437.

Xuereb K (2015) Future-proofing Buildings: a Novel Approach to Measure the Performance of Building Structures. PhD thesis, University College London, London, UK.

Xuereb K and Parkin I (2016) Adapting building structures to new uses in the future. Proceedings of the Institution of Civil Engineers Engineering Sustainability 169(6): 233-242, https://doi.org/10.1680/ jensu.15.00043.

Yang S and Lu N (2013) Gauge factor and stretchability of silicon-onpolymer strain gauges. Sensors 13(7): 8577-8594, https://doi.org/10. 3390/s 130708577.

Yin G, Hu N and Karube Y (2011) A carbon nanotube/polymer strain sensor with linear and anti-symmetric piezoresistivity. Journal of Composite Materials 45(12): 1315-1323, https://doi.org/10.1177/ 0021998310393296 
Smart Infrastructure and Construction Volume 172 Issue 3
Novel carbon-nanotube-enhanced composite load sensor to monitor the whole-life structural performance of buildings

Xuereb and Parkin
Yun YH, Kang I, Gollapudi R et al. (2005) Multifunctional carbon nanofiber/nanotube smart materials. Proceedings of SPIE 5763: 184-195, https://doi.org/10.1117/12.600276.
Zhang W, Suhr J and Koratkar N (2016) Carbon nanotube/polycarbonate composites as multifunctional strain sensors. Journal of Nanoscience and Nanotechnology 6(4): 960-964, https://doi.org/10.1166/jnn.2006.171.

\section{How can you contribute?}

To discuss this paper, please email up to 500 words to the editor at journals@ice.org.uk. Your contribution will be forwarded to the author(s) for a reply and, if considered appropriate by the editorial board, it will be published as discussion in a future issue of the journal.

Proceedings journals rely entirely on contributions from the civil engineering profession (and allied disciplines). Information about how to submit your paper online is available at www.icevirtuallibrary.com/page/authors, where you will also find detailed author guidelines. 